\title{
The presence of Down syndrome is not a risk factor in complete atrioventricular septal defect repair
}

Ruediger Lange, MD, PhD, ${ }^{a}$ Thomas Guenther, MD, ${ }^{a}$ Raymonde Busch, MS, ${ }^{\mathrm{c}}$ John Hess, MD, PhD, ${ }^{\mathrm{b}}$ and Christian Schreiber, MDa

From the Departments of Cardiovascular Surgery ${ }^{\mathrm{a}}$ and Pediatric Cardiology, ${ }^{\mathrm{b}}$ German Heart Center, Clinic at the Technical University; and Institute of Medical Statistics and Epidemiology, Technical University, ${ }^{\mathrm{c}}$ Munich, Germany.

Received for publication Sept 21, 2006; revisions received Jan 2, 2007; accepted for publication Jan 8, 2007.

Address for reprints: Thomas Günther, MD, Klinik für Herz und Gefäßchirurgie, Deutsches Herzzentrum, Klinik an der Technischen Universität München, Lazarettstraße 36, D-80636 München (E-mail: Guenther@ dhm.mhn.de).

J Thorac Cardiovasc Surg 2007;134:304-10 $0022-5223 / \$ 32.00$

Copyright (๑) 2007 by The American Association for Thoracic Surgery

doi:10.1016/j.jtcvs.2007.01.026
Objective: Down syndrome is frequently associated with complete atrioventricular septal defect. The aim of this retrospective study was to evaluate the impact of Down syndrome on morphologic features, surgical management, and perioperative and long-term mortality in patients with complete atrioventricular septal defect.

Methods: Between October 1974 and March 2005, 476 patients with complete atrioventricular septal defect underwent surgery, 341 (71.6\%) of whom had Down syndrome. A total of 336 patients $(70.6 \%)$ underwent primary repair, 95 patients (20\%) underwent palliative surgery on an average of $3.4 \pm 2.9$ years before repair, and 45 patients $(9.4 \%)$ had no subsequent repair.

Results: Patients with Down syndrome (group D) exhibited higher preoperative pulmonary artery pressure $(P=.012)$ and resistance $(P=.006)$ compared with patients without Down syndrome (group ND). Rastelli types B and C were more frequent in group $\mathrm{D}(P=.002)$, but left atrioventricular valve anomalies were more frequent in group ND $(P=.03)$. No difference was seen regarding operative strategy $(P=.117)$ and timing of repair $(P=.32)$. Thirty-day mortality after complete atrioventricular septal defect repair was $4.9 \%$ in group D compared with $5.6 \%$ in group ND. Actuarial survival after 20 years is $84 \% \pm 2.5 \%$ (group D) and $75 \% \pm 5.7 \%$ (group ND) $(P=.252)$, and freedom from left atrioventricular valve-related reoperation is $82 \% \pm 2.9 \%$ (group D) and $72 \% \pm 5.3 \%$ (group ND) $(P=.004)$. Reinterventions on the left atrioventricular valve were required significantly more often in patients in group ND.

Conclusions: The presence of Down syndrome in patients with complete atrioventricular septal defect is not a risk factor for surgical repair. Because of the early development of pulmonary vascular disease, primary repair should be performed within the first 6 months of life. In the long term, reintervention on the left atrioventricular valve is more often required in children with a normal chromosomal pattern.

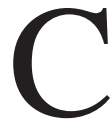

omplete atrioventricular septal defect (CAVSD) is frequently $(60 \%-86 \%)$ associated with Down syndrome. ${ }^{1-7}$ Clinically relevant differences have been identified in children with CAVSD with and without Down syndrome. ${ }^{8,9}$ Thus, left-sided obstructions and right ventricular dominance, as well as left atrioventricular valve (LAVV) abnormalities such as double orifice valve and single papillary muscle, seem to be more prevalent in children with a normal chromosomal pattern, whereas Rastelli types B and C are more often found in patients with Down syndrome. ${ }^{8,9}$ Early progression of pulmonary vascular obstructive disease has been reported especially in patients with CAVSD associated with Down syndrome. ${ }^{10-12}$ Furthermore, children with Down syndrome may be at increased risk for perioperative and long-term mortality, ${ }^{1,13}$ and have a predisposition to more operative complications (eg, atelectasis and pulmonary edema) requiring a 


\section{Abbreviations and Acronyms \\ CAVSD $=$ complete atrioventricular septal defect \\ LAVV = left atrioventricular valve}

longer duration of mechanical ventilation, intensive care, and hospital stay. ${ }^{14}$ Nevertheless, previous studies have suggested an improved outcome for patients with Down syndrome undergoing surgery for CAVSD. ${ }^{5,6}$ Thus, to clarify these controversies, we analyzed the perioperative and long-term outcome in all children who underwent surgical correction for CAVSD in our center, with special emphasis on the comparison of patients with and without Down syndrome. This analysis may help to advise parents and physicians more precisely about the operative risk and longterm morbidity of this cardiac defect.

\section{Materials and Methods}

Data from 476 patients with CAVSD who underwent operation between October 1974 and March 2005 at the German Heart Center, Munich, were analyzed. Patients with major associated cardiovascular anomalies (tetralogy of Fallot, double-outlet right ventricle, transposition of the great arteries, and total anomalous pulmonary venous drainage) and patients with intermediate type of atrioventricular septal defect were not included in the analysis. Of the 476 children, 341 (71.6\%) presented with Down syndrome (group D) and 135 presented with a normal chromosomal pattern (group ND). Overall, 303 patients (64\%) (group ND n $=88$ [65\%], group $\mathrm{D} n=215[63 \%])$ exhibited additional minor cardiac anomalies (Table 1). Twenty-six patients $(5.5 \%)$ had right $(n=21)$ or left $(n=5)$ ventricular dominance. Extracardiac anomalies were observed in 39 patients, including duodenal atresia/stenosis, Hirschsprung's disease, congenital tracheal stenosis, Apert syndrome, and CHARGE association. A total of 336 patients (71\%) had primary repair, 89 patients $(66 \%)$ in group D and 247 patients (72\%) in group ND. Age at primary repair ranged between 1 month and 10.3 years (mean $0.9 \pm 1.3$ years, median: 0.53 years). A total of 152 patients $(45.2 \%)$ were younger than 6 months. Weight varied between 1.3 and $23.2 \mathrm{~kg}$ (median: $5.3 \mathrm{~kg}$ ). A total of 36 patients underwent primary repair weighing less than $4000 \mathrm{~g}$. Mean age at primary repair was $0.8 \pm 1.0$ years in group $\mathrm{D}$ and $1.3 \pm 1.8$ years in group ND. A total of 95 patients $(20 \%)$ underwent palliative surgery 5 days to 17.8 years (mean: $3.4 \pm 2.9$ years median: 2.8 years) before repair. In a group of 45 patients (9.4\%), palliative surgery remained the only option. In the patient group with previous pulmonary artery banding, age at repair ranged from 1.4 months to 18 years (mean: $3.7 \pm 3.2$ years, median: 3.1 years), and weight ranged from 2.8 to $46.2 \mathrm{~kg}$ (median: $12 \mathrm{~kg}$ ).

According to the intraoperatively assessed Rastelli classification, ${ }^{15} 64 \%$ of the patients who underwent corrective surgery presented with type A, 3\% presented with type B, and 33\% presented with type C. Eighteen of 431 patients (4.2\%) who underwent CAVSD repair presented with LAVV anomalies (double orifice mitral valve $[\mathrm{n}=4]$, single left ventricular papillary muscle $[n=8]$, dysplastic valve with extreme deficiency of LAVV tissue $[n=6])$. A total of 311 patients underwent cardiac catheterization before repair, which included hemodynamic evaluation of systemic and pulmonary blood flow and resistance (Table 2). Catheterization was performed in $95 \%$ of the patients who underwent operation between 1974 and 1994 and in $37 \%$ of the patients who underwent operation in the last decade.

\section{Operative Technique}

In 172 patients $(40 \%)$ of the early study period, repair was performed using hypothermic circulatory arrest (mean circulatory arrest time $60 \pm 8$ minutes). Continuous extracorporeal circulation and moderate hypothermia (rectal temperature $24^{\circ} \mathrm{C}-28^{\circ} \mathrm{C}$ ) were used in the remaining patients and is the currently used technique. Mean cardiopulmonary bypass time at primary repair was $114 \pm$ 36 minutes, and mean aortic crossclamp time was $80 \pm 21$ min-

TABLE 1. Incidence of minor cardiovascular anomalies in 476 patients with complete atrioventricular septal defect

\begin{tabular}{|c|c|c|c|c|c|c|c|}
\hline \multirow[b]{2}{*}{ Patients (n) } & \multicolumn{2}{|c|}{ All patients } & \multicolumn{2}{|c|}{ Group D } & \multicolumn{2}{|c|}{ Group ND } & \multirow[b]{2}{*}{$\begin{array}{c}P \text { valu } \\
.62\end{array}$} \\
\hline & $\begin{array}{l}\text { No. } \\
476\end{array}$ & $\%$ & $\begin{array}{l}\text { No. } \\
341\end{array}$ & $\%$ & $\begin{array}{l}\text { No. } \\
135\end{array}$ & $\%$ & \\
\hline ASD II/PFO & 180 & 37.8 & 137 & 40.2 & 43 & 31.8 & .678 \\
\hline PDA & 135 & 28.4 & 112 & 32.8 & 23 & 17.0 & .001 \\
\hline LPSVC & 29 & 6.1 & 15 & 4.4 & 14 & 10.4 & .013 \\
\hline Common atrium & 12 & 2.5 & 2 & 0.6 & 10 & 7.4 & $<.001$ \\
\hline Azygos extension of IVC & 10 & 2.1 & 0 & 0 & 10 & 7.4 & $<.001$ \\
\hline Anomalous right subclavian artery & 10 & 2.1 & 6 & 1.8 & 4 & 3.0 & .402 \\
\hline Additional VSDs & 14 & 2.9 & 8 & 2.3 & 6 & 4.4 & .216 \\
\hline Subaortic stenosis & 7 & 1.5 & 3 & 0.9 & 4 & 3.0 & .089 \\
\hline Dextrocardia & 2 & 0.4 & 0 & 0 & 2 & 1.5 & .024 \\
\hline Congenital heart block & 2 & 0.4 & 0 & 0 & 2 & 1.5 & .024 \\
\hline PAPVC & 2 & 0.4 & 1 & 0.3 & 1 & 0.7 & .496 \\
\hline Agenesia of IVC & 1 & 0.2 & 0 & 0 & 1 & 0.7 & .112 \\
\hline
\end{tabular}

$A S D$, Atrial septal defect; $I V C$, inferior vena cava; $L P S V C$, left persistent superior vena cava; $P A P V C$, partial anomalous pulmonary venous connection; $P D A$, patent ductus arteriosus; PFO, patent foramen ovale; $V S D$, ventricular septal defect. 
TABLE 2. Cardiac catheterization data before primary repair in patients with and without Down syndrome

\begin{tabular}{|c|c|c|c|c|}
\hline Patients (n) & $\begin{array}{c}\text { All patients } \\
\text { mean } \pm \text { SD } \\
336\end{array}$ & $\begin{array}{c}\text { Group D } \\
\text { mean } \pm \text { SD } \\
247\end{array}$ & $\begin{array}{c}\text { Group ND } \\
\text { mean } \pm \text { SD } \\
89\end{array}$ & $P$ value \\
\hline $\mathrm{RAP}$ (mean) (mm Hg) & $5.8 \pm 2.4$ & $5.8 \pm 2.4$ & $6.0 \pm 2.5$ & .494 \\
\hline LAP (mean) (mm Hg) & $6.5 \pm 2.7$ & $6.6 \pm 2.7$ & $6.4 \pm 2.8$ & .762 \\
\hline RV (systolic) (mm Hg) & $73.0 \pm 13.2$ & $73.4 \pm 11.7$ & $71.1 \pm 16.2$ & .516 \\
\hline PAP (systolic) (mm Hg) & $68.8 \pm 15.1$ & $70.5 \pm 12.4$ & $64.9 \pm 19.6$ & .012 \\
\hline Room air $0 p / 0 s$ & $3.3 \pm 2.1$ & $3.2 \pm 2.2$ & $3.4 \pm 1.8$ & .539 \\
\hline Room air $\mathrm{Rp} / \mathrm{Rs}$ & $0.35 \pm 0.3$ & $0.39 \pm 0.3$ & $0.25 \pm 0.2$ & .004 \\
\hline Room air PVRI $\left(\mathrm{U} / \mathrm{m}^{2}\right)$ & $4.4 \pm 3.0$ & $4.8 \pm 3.0$ & $3.5 \pm 2.9$ & .006 \\
\hline Left-to-right shunt & $65.6 \pm 16.5$ & $64.4 \pm 16.6$ & $68.6 \pm 15.9$ & .105 \\
\hline
\end{tabular}

$R A P$, Right atrial pressure; $L A P$, left atrial pressure; $R V$, right ventricle; $P A P$, pulmonary artery pressure; $Q p / Q s$, pulmonary-to-systemic flow ratio; $R p / R s$, pulmonary-to-systemic resistance ratio; $P V R I$, pulmonary vascular resistance index; $S D$, standard deviation.

utes. In 32 cases (7.4\%) (mainly in the early study period: 19741978) repair was performed using the 1-patch technique described by Rastelli and colleagues. ${ }^{16}$ Since 1978 , the 2-patch technique has been applied. ${ }^{17}$ The ventricular septal defect was closed with a continuous 4.0 to 6.0 Prolene suture to affix a semicircular Dacron patch keeping the suture line on the right side of the crest of the ventricular septum. The valve leaflets were fixed on the upper edge of the patch with interrupted sutures, starting at the central meeting point of the anterior and posterior leaflets. Any attempt was made to close the anterior commissure or "cleft" of the LAVV as completely as possible. In 12 patients, the "cleft" had to be left open to prevent LAVV stenosis. In general, the LAVV diameter was assessed intraoperatively with a Hegar dilator and compared with the nomograms of Rowlatt and coworkers. ${ }^{18}$ A separate Dacron patch was then sutured to the superior aspect of the ventricular patch to close the atrial defect. In cases of sparse tissue in front of the coronary sinus, the suture line was passed superior to the atrioventricular node, placing the coronary sinus to the left side ( $n=26$ patients); otherwise the atrial patch was anchored with superficial stitches along the valve ring, avoiding the conduction system. Additional surgical procedures at repair included closure of patent ductus arteriosus in 84 patients, debanding in 94 patients (followed by patch enlargement of the pulmonary artery in 26 patients and pulmonary artery resection with end-to-end anastomosis in 2 patients), ligation of left superior caval vein in 7 patients, resection of subaortic stenosis in 7 patients, and closure of additional muscular ventricular septal defects in 5 patients.

Pulmonary artery banding was performed in cases with high pulmonary vascular resistance $\left(>6 \mathrm{U} / \mathrm{m}^{2}\right)$ not reactive to oxygen with substantial left-to-right shunt, hypoplastic left ventricle (left ventricular end-diastolic volume $<50 \%$ of predicted normal), or coexisting coarctation.

\section{Follow-up}

Operative survivors are regularly followed up at 3-, 6-, or 12month intervals at the outpatient department of the Department of Pediatric Cardiology at the German Heart Center, Munich, including physical examination, electrocardiography, radiography, and echocardiography. Follow-up data were obtained from medical records of follow-up visits and additional telephone interviews with the family physicians.
As of December 2005, 368 of 431 patients who underwent CAVSD repair are alive. The follow-up is $95 \%$ complete. Twentyfour patients were lost to follow-up. The follow-up extends up to 30 years (mean $6.9 \pm 7.2$ years, with a cumulative total of 3262 patient-years); $88 \%$ of the survivors are in New York Heart Association class I, $87 \%$ are in sinus rhythm, and $83 \%$ are without cardiac medication.

\section{Statistical Analysis}

Kaplan-Meier analysis was used to study patient and event-free survival status. The log-rank test was used to ascertain differences between groups. The chi-square test (for categoric data) and MannWhitney test (for measured data) were used to determine statistical significance. Univariate analyses were used to assess whether there was a relationship between outcome (30-day mortality) and possible predictors. Significant factors were entered into a multivariate proportional hazard model (multiple logistic regression) to assess the independent impact of potential risk factors. All data were analyzed with the Statistical Package for the Social Sciences software, release 11.5 (SPSS, Chicago, Ill).

\section{Results}

\section{Preoperative Patient Data}

Fifty-six percent of the patients in group D and $61.5 \%$ in group ND were female $(P=.276)$. Patients in group $\mathrm{D}$ showed a significantly higher rate of Rastelli types B (4\% vs $1 \%)$ and type $\mathrm{C}(37 \%$ vs $23 \%)$ compared with those in group ND $(P=.002)$. Sex and the common atrioventricular valve morphology (Rastelli type) did not affect survival (Table 3). There was no difference in the overall incidence of minor associated cardiac anomalies $(P=.62)$ or the incidence of extracardiac anomalies $(P=.11)$.

However, in a subgroup analysis we found a significant difference in the incidence of minor cardiac anomalies, such as patent ductus arteriosus, left persistent superior vena cava, common atrium, azygos extension of inferior vena cava, and dextrocardia (Table 1). The incidence of LAVV anomalies (double orifice mitral valve, single papillary mus- 
TABLE 3. Analysis of potential risk factors associated with 30-day mortality in patients who underwent complete atrioventricular septal defect repair

\begin{tabular}{|c|c|c|c|c|}
\hline Factor & Univariate $P$ value & Multivariate $P$ value & Odds ratio & Confidence interval $(95 \%)$ \\
\hline Female sex & .076 & & & \\
\hline Down syndrome & 677 & & & \\
\hline Rastelli type & .016 & & & \\
\hline $\mathrm{Rp} / \mathrm{Rs}>0.4$ & .414 & & & \\
\hline Minor cardiovascular anomalies & .590 & & & \\
\hline Unbalanced ventricle & .921 & & & \\
\hline Coexisting $\mathrm{Co} A$ & .549 & & & \\
\hline LAVV anomalies & .002 & .007 & 6.08 & $1.62-22.8$ \\
\hline Age at repair $(<6 \mathrm{mo})$ & .110 & .004 & 4.54 & $1.61-12.8$ \\
\hline Operative technique: (1-patch technique) & .027 & & & \\
\hline Date of operation $(<1990)$ & .040 & .004 & 4.79 & $1.65-13.9$ \\
\hline Previous PAB & .613 & & & \\
\hline
\end{tabular}

$A V$, Atrioventricular; $C O A$, coarctation of the aorta; $R p / R s$, pulmonary-to-systemic resistance ratio; $P A B$, pulmonary artery banding; $L A V V$, left atrioventricular valve.

cle, dysplastic valve) was significantly lower among patients in group $\mathrm{D}$ compared with group $\mathrm{ND}(P=.03)$.

Analysis of the preoperative hemodynamic variables of both patient groups (Table 2) revealed that patients in group D exhibited significantly higher pulmonary vascular resistance (mean: $4.8 \pm 3.0$ [group D] vs $3.5 \pm 2.9$ [group ND], $P=.006)$ and pulmonary-to-systemic resistance ratios (mean: $0.39 \pm 0.3$ [group D] vs $0.25 \pm 0.2$ [group ND], $P=.004)$ compared with patients in group ND. The same difference in these pulmonary vascular parameters was found for the subgroups of patients aged less than 6 months at primary repair. No significant difference was found in regard to the surgical strategy $(P=.117)$ and timing of repair ( $<6$ vs $\geq 6$ months) $(P=.32)$. Seventy-two percent of the patients in group D and $66 \%$ of the patients in group ND underwent primary repair; cardiopulmonary bypass times were equal for both groups (median: 107 minutes [group D] vs 110 minutes [group ND] $(P=.91)$. Patients spent an average of $8.5 \pm 8.6$ days in the intensive care unit with no significant difference between both groups (group D $[8.1 \pm 7.6$ days], group ND [9.7 \pm 10.7 days], $P=.789$ ). However, patients of group D required a longer mechanical ventilation time (median: 3 days) than patients in group ND (median 2 days) $(P=.012)$.

Overall 30-day mortality for all patients who underwent CAVSD repair was $5.1 \%$ (22/431). Of the 336 patients who underwent primary correction, 18 (5.4\%) died early. Despite a trend toward primary repair in young infants $(<6$ months), 30-day mortality could be reduced from $8.6 \%$ in the period from 1974 to 1989 to $3.4 \%$ in the period from 1990 to 2004. Thirty-day mortality after primary repair showed no significant difference between both patient groups (group D 5.3\%, group ND 5.6\%, $P=.534$ ). There was also no difference in 30-day mortality when the subgroups of patients with age at primary repair less than 6 months and more than 6 months were analyzed. Of the 95 patients who had prior palliative surgery, $6(6 \%)$ died within 30 days postoperatively. Multiple logistic regression analysis revealed young age at repair ( $<6$ months), earlier date of operation $(<1990)$, and associated LAVV anomalies as significant risk factors for 30-day mortality (Table 3). Age less than 6 months, however, was a risk factor only in the early study period. Overall, 40 children $(9.3 \%)$ died late after repair, $25(8.1 \%)$ in group D and $15(12.1 \%)$ in group

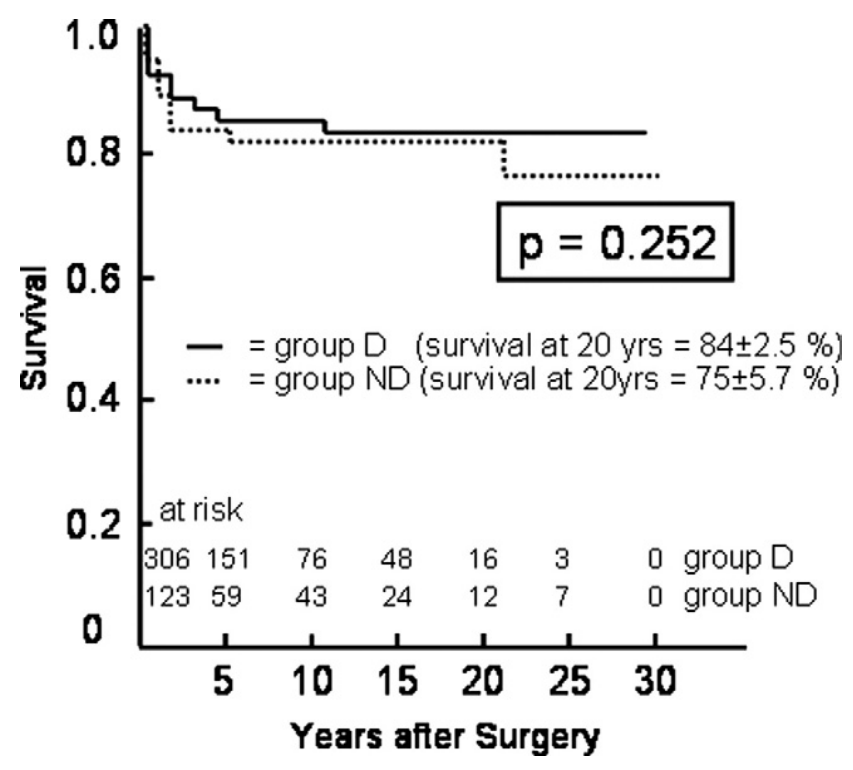

Figure 1. Actuarial survival after CAVSD repair. Kaplan-Meier estimate of survival for patients with and without Down syndrome. The actuarial survival at 20 years is $84 \% \pm 2.5 \%$ for patients with Down syndrome and $75 \% \pm 5.7 \%$ for those without. CAVSD, Complete atrioventricular septal defect. 


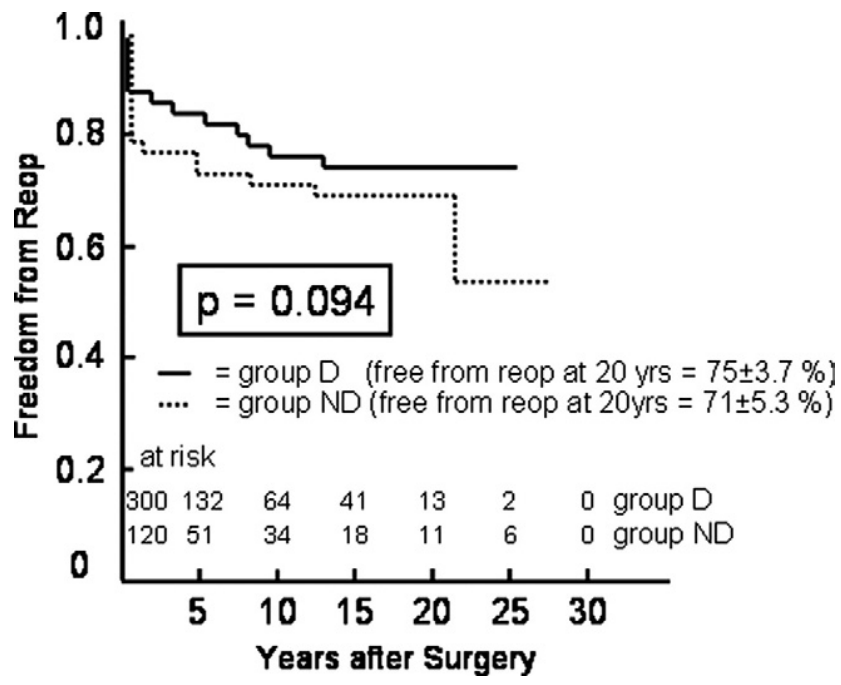

Figure 2. Freedom from reoperation after CAVSD repair. KaplanMeier estimate of freedom from reoperation for patients with and without Down syndrome. Freedom from reoperation at $\mathbf{2 0}$ years is $\mathbf{7 5} \% \pm \mathbf{3 . 7} \%$ for patients with Down syndrome and $71 \% \pm \mathbf{5 . 3} \%$ for those without. CAVSD, Complete atrioventricular septal defect.

ND. Late deaths were mainly due to progressive cardiac failure and late pulmonary infections. Actuarial survival 20 years after CAVSD repair was $84 \% \pm 2.5 \%$ in group D and $75 \% \pm 5.7 \%$ in group ND $(P=.252)$ (Figure 1$)$.

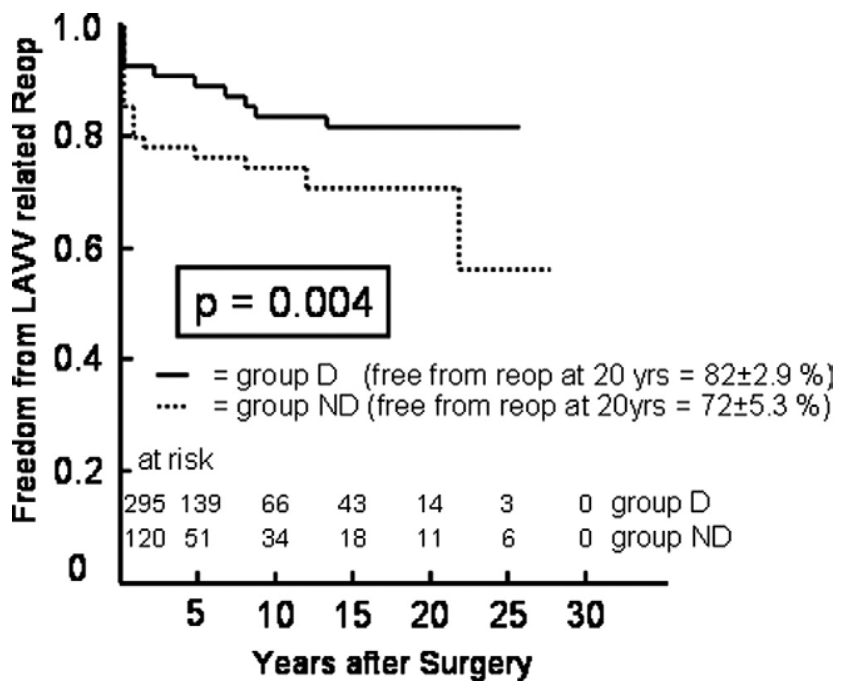

Figure 3. Freedom from LAVV-related reoperation after CAVSD repair. Kaplan-Meier estimate of freedom from LAVV-related reoperation for patients with and without Down syndrome. Freedom from reoperation at 20 years is $82 \% \pm 2.9 \%$ for patients with Down syndrome and $72 \% \pm 5.3 \%$ for those without. LAVV, Left atrioventricular valve; CAVSD, Complete atrioventricular septal defect.
Incidence of Reoperation

Reoperation was defined as a second operation after CAVSD repair requiring cardiopulmonary bypass. Within an observation period of more than 30 years, 44 patients $(11.1 \%)$ in group D and 29 patients $(22.7 \%)$ in group ND required a reoperation 7 days to 8.0 years (mean $1.2 \pm 2.0$ years) after primary repair. Thus, freedom from reoperation at 20 years in group D was $75 \% \pm 3.7 \%$ compared with $71 \% \pm 5.3 \%$ in group ND (Figure 2); the difference was not significant $(P=.094)$. In contrast, freedom from reoperation on the LAVV at 20 years was $82 \% \pm 2.9 \%$ (group D) compared with $72 \% \pm 5.3 \%$ (group ND) $(P=$ .004) (Figure 3). Approximately half of the patients (48\%) underwent reoperation within 3 months after repair.

The main indication $(82 \%)$ for reoperation was significant LAVV incompetence. Repair of LAVV was possible in most cases, except in 27 patients who required valve replacement. Both patient groups showed no significant difference in the need for valve replacement $(P=.071)$. Other indications for reoperation were subaortic stenosis, recurrent ventricular septal defect, and tricuspid valve incompetence. The number and type of reoperation are summarized in Table 4. Overall, 24 patients, $8(6.3 \%)$ in group ND and $16(5.1 \%)$ in group $\mathrm{D}$, required a permanent pacemaker, mainly for postoperative complete atrioventricular block. There was no difference in the incidence of postoperative complete atrioventricular block between both patient groups $(P=.856)$.

\section{Discussion}

The majority of patients who are referred for repair of CAVSD exhibit Down syndrome. Controversy exists in the literature as to how the presence of Down syndrome may

TABLE 4. Incidence and type of reoperation after complete atrioventricular septal defect repair

\begin{tabular}{lr}
\hline LAVV repair & 21 \\
LAVV replacement & 13 \\
LAVV repair + VSD closure & 9 \\
LAVV repair + resection of subaortic stenosis & 6 \\
LAVV repair + RAVV repair & 4 \\
LAVV repair + RAVV repair + VSD closure & 4 \\
VSD closure & 4 \\
Resection of subaortic stenosis & 3 \\
RAVV repair + VSD closure & 2 \\
Other & 7 \\
Total & 73
\end{tabular}

$L A V V$, Left atrioventricular valve; RAVV, right atrioventricular valve; $V S D$, ventricular septal defect. Other reoperations $=$ coarctation of the aorta resection (1), tricuspid valve repair (1), mitral valve replacement + VSD closure (1), mitral valve replacement + resection of subaortic stenosis (1), mitral valve repair + atrial septal defect + VSD closure (1), tricuspid valve repair + atrial septal defect closure (1), resection of subaortic stenosis + aortic valve repair (1). 
influence the perioperative results and the long-term outcome of these patients.

\section{Pulmonary Predisposition in Down Syndrome}

CAVSD in patients with Down syndrome has been reported to be associated with an unusually high incidence of pulmonary hypertension and pulmonary vascular obstructive disease. ${ }^{10,11}$ On the basis of histologic specimens from patients with and without Down syndrome, Yamaki and associates $^{11}$ reported a more severe form of pulmonary vascular disease in patients with Down syndrome, with significant differences in the amount of intimal lesions and medial thickness of the small pulmonary arteries. On the basis of these findings, early repair within the first 6 months of life was recommended. Rizzoli and coworkers ${ }^{19}$ found a significantly higher pulmonary vascular resistance (4.5 $\mathrm{U} / \mathrm{m}^{2}$ vs $1.93 \mathrm{U} / \mathrm{m}^{2}$ ) in patients with Down syndrome compared with patients without. As other studies have, ${ }^{12,20}$ we also found a significant difference in pulmonary vascular resistance (mean: 4.8 vs $3.5 \mathrm{U} / \mathrm{m}^{2}$ ) and pulmonary-tosystemic resistance ratio $(0.39$ vs 0.25$)$ in patients with and without Down syndrome, regardless of the age at primary repair. Children with Down syndrome may also have a predisposition to more perioperative complications, including pulmonary atelectasis and pulmonary edema, requiring a longer duration of mechanical ventilation, intensive care stay, and hospitalization. ${ }^{14,19}$ Although we found the duration of mechanical ventilation to be longer in patients of group $\mathrm{D}$, the total time spent in the intensive care unit was not different. Thus, the less favorable pulmonary predisposition in Down syndrome had no influence on the need for early postoperative care.

\section{Left-sided Valve Morphology}

Differences also exist regarding the LAVV morphology and the presence of left ventricular obstructive lesions. ${ }^{8,9}$ AlexiMeskishvili and associates ${ }^{3}$ found an incidence of more complicated LAVV anomalies in $10.6 \%$ of patients with Down syndrome compared with $17.6 \%$ in those without. This difference did not reach significance. In our series, children with a normal chromosomal pattern presented with a significantly higher incidence of LAVV anomalies (double orifice mitral valve, single papillary muscle, dysplastic valve). These anomalies have been identified as independent risk factors for 30-day mortality. ${ }^{3,5}$ Marino ${ }^{9}$ stated that Rastelli type $\mathrm{C}$ is more prevalent in patients with Down syndrome, a finding that could be confirmed in our study, because patients with Down syndrome showed a significantly higher rate of Rastelli types B (4\% vs $1 \%$ ) and type C (36\% vs 23\%) compared with patients without Down syndrome. However, in our study the Rastelli type had no influence on outcome after CAVSD repair. We also found no significant difference in the incidence of minor associ- ated cardiac anomalies in patients with or without Down syndrome, similar to other studies. ${ }^{19}$

\section{Survival}

Despite the above-mentioned differences in patients with CAVSD with and without Down syndrome, we could not identify the presence of Down syndrome to be an independent incremental risk factor. Thirty-day mortality ( $5.3 \%$ vs $5.6 \%)$ and 20 -year survivals $(84 \% \pm 2.5 \%$ vs $75 \% \pm 5.7 \%)$ were not found to be different. In contrast with Formigari and coworkers, ${ }^{6}$ who reported a higher prevalence of pulmonary artery banding procedures in children with normal chromosomal pattern, we found no significant difference between both patient groups regarding the operative strategy (primary repair vs 2 -stage repair) $(P=.117)$ and the age at repair $(<6$ months vs $\geq 6$ months $)(P=.32)$. Furthermore, our results compare favorably with other studies, ${ }^{2,3,5,6,19}$ because no differences in 30-day mortality and long-term survival were detected. Thirty-day mortality was 9.7\% and $16 \%$ in children with Down syndrome and $11.1 \%$ and $12 \%$ in children without Down syndrome in the studies by Alexi-Meskishvili and coworkers ${ }^{3}$, and Al-Hay and associates ${ }^{5}$ respectively. The difference was not significant in either investigation. These data, however, are in contrast with those of Morris and colleagues, ${ }^{1}$ who reported on 59 children with a 2-year survival after repair of $77 \% \pm 6 \%$ in patients with Down syndrome compared with $100 \%$ in children without Down syndrome. All deaths in their series (10/59) occurred in children with Down syndrome and were cardiac related. In 1985, Bull and colleagues ${ }^{21}$ questioned the advisability of repairing CAVSD in patients with Down syndrome, on the assumption that early surgery carries a high risk for an uncertain prospect. Bull and coworkers reported a survival of $80 \%$ at 15 years in 67 patients with medical management and recommended medical treatment, unless a unit can offer exceptional surgical results. Currently, primary repair of CAVSD is safe and can be accomplished with an operative mortality less than $4 \%$ even in young infants, thus offering excellent short- and long-term results. 2,22

\section{Reoperation}

In our series, $11.1 \%$ of the patients in group D and $22.7 \%$ in group ND required reoperation. Overall freedom from reoperation at 20 years in children with Down syndrome was $75 \% \pm 3.7 \%$, compared with $71 \% \pm 5.3 \%$ in children with normal chromosomes; the difference was not significant $(P$ $=.094$ ). However, patients in group ND required significantly more reoperations on the LAVV, presumably because LAVV anomalies (double orifice mitral valve, single papillary muscle) were more prevalent in patients without Down syndrome, as has been described by others. ${ }^{5} \mathrm{An}$ increased risk for reoperation in children without Down 
syndrome has been described by various investigators. ${ }^{5,6,23}$ Formigari and associates ${ }^{6}$ reported a higher prevalence of recurrent subaortic stenosis in children with normal chromosomes, and in their study reintervention on the LAVV was also more frequent in patients without Down syndrome.

\section{Conclusions}

Because of a tremendous evolution in pediatric cardiac surgery, primary repair of CAVSD is safe today and can be accomplished with an operative mortality less than $4 \%$ even in young infants, thus offering excellent short- and longterm results. In our experience the presence of Down syndrome in patients with CAVSD does not affect operative strategy, timing of repair, or postoperative outcome and is thus not considered an additional risk factor. Physicians and parents should be aware that, in the long term, reintervention on the LAVV may be required more often in children with a normal chromosomal pattern.

\section{References}

1. Morris CD, Magilke D, Reller M. Down's syndrome affects results of surgical correction of complete atrioventricular canal. Pediatr Cardiol. 1992;13:80-4.

2. Tweddell JS, Litwin SB, Berger S, Friedberg DZ, Thomas JP, Frommelt PC, et al. Twenty-year experience with repair of complete atrioventricular septal defects. Ann Thorac Surg. 1996;62:419-24.

3. Alexi-Meskishvili V, Ishino K, Dähnert I, Uhlemann F, Weng Y, Lange PE, et al. Correction of complete atrioventricular septal defects with the double-patch technique and cleft closure. Ann Thorac Surg. 1996;62:519-25.

4. Günther T, Mazzitelli D, Haehnel CJ, Holper K, Sebening F, Meisner $\mathrm{H}$. Long-term results after repair of complete atrioventricular septal defects: analysis of risk factors. Ann Thorac Surg. 1998;65:754-60.

5. Al-Hay AA, MacNeill SJ, Yacoub M, Shore DF, Shinebourne EA. Complete atrioventricular septal defect, Down syndrome, and surgical outcome: risk factors. Ann Thorac Surg. 2003;75:412-21.

6. Formigari R, DiDonato RM, Gargiulo G, DiCarlo D, Feltri C, Picchio FM, et al. Better surgical prognosis for patients with complete atrioventricular septal defect and Down's. syndrome. Ann Thorac Surg. 2004; 78:666-72.

7. Masuda M, Kado H, Tanoue Y, Fukae K, Onzuka T, Shiokawa Y, et al Does Down syndrome affect the long-term results of complete atrioventricular septal defect when the defect is repaired during the first year of life. Eur J Cardiothorac Surg. 2005;27:405-9.
8. De Biase L, Di Ciommo V, Ballerini L, Bevilaqua M, Marcelletti C, Marino B. Prevalence of left-sided obstructive lesions in patients with atrioventricular canal without Down's syndrome. J Thorac Cardiovasc Surg. 1986;31:467-9.

9. Marino B. Complete atrioventricular septal defect in patients with and without Down's syndrome. Ann Thorac Surg. 1994;57:1687 (letter to the editor).

10. Chi TPL, Krovetz LJ. The pulmonary vascular bed in children with Down syndrome. J Pediatr. 1975;86:533-8.

11. Yamaki S, Yasui H, Kado H, Yonenaga K, Nakamura Y, Kikuchi T, et al. Pulmonary vascular disease and operative indications in complete atrioventricular canal defect in early infancy. Am J Cardiol. 1983;51:1503-6.

12. Clapp S, Perry BL, Farooki ZQ. Down's syndrome, complete atrioventricular canal and pulmonary vascular obstructive disease. J Thorac Cardiovasc Surg. 1990;100:115-21.

13. Reller MD, Morris CD. Is Down syndrome a risk factor for poor outcome after repair of congenital heart defects? J Pediatr. 1998;132: 738-41.

14. Morray JP, MacGillivray R, Duker G. Increased perioperative risk following repair of congenital heart disease in infants with Down syndrome. Anesthesiology. 1986;65:221-4.

15. Rastelli GC, Kirklin JW, Titus JL. Anatomic observations on complete form of persistent common atrioventricular canal with special reference to atrioventricular valves. Mayo Clin Proc. 1966;41:296-308.

16. Rastelli GC, Ongley PA, Kirklin JW, McGoon DC. Surgical repair of the complete form of persistent common atrioventricular canal. J Thorac Cardiovasc Surg. 1968;55:299-308.

17. Carpentier A. Surgical anatomy and management of the mitral components of atrioventricular canal defects. In: Anderson RH, Shinebourne EA, eds. Paediatric Cardiology. Edinburgh, London, New York: Churchill Livingstone; 1978:477-90.

18. Rowlatt JF, Rimaldi JMA, Lev M. The quantitative anatomy of the normal child's heart. Pediatr Clin North Am. 1963;10:499-588.

19. Rizzoli G, Mazzucco A, Maizza F, Daliento L, Rubino M, Tursi V, et al. Does Down syndrome affect prognosis of surgically managed atrioventricular canal defects? J Thorac Cardiovasc Surg. 1992;104: 945-53.

20. Hals J, Hagemo PS, Thaulow E, Sorland SJ. Pulmonary vascular resistance in complete atrioventricular septal defect. A comparison between children with and without Down's syndrome. Acta Paediatr. 1993;82:595-8

21. Bull C, Rigby ML, Shinebourne EA. Should management of complete atrioventricular canal defect be influenced by coexistent Down syndrome? Lancet. 1985;1:117-49.

22. Yasui H, Nakamura Y, Kado H, Yonenaga K, Shiokawa Y, Fusazaki N, et al. Primary repair of complete atrioventricular canal: recommendation for early primary repair. J Cardiovasc Surg. 1990;31:498-504.

23. Weintraub RG, Brawn WJ, Venables AW, Mee RB. Two-patch repair of complete atrioventricular septal defect in the first year of life. J Thorac Cardiovasc Surg. 1990;99:320-6. 